\title{
Pace of dental contract reform could accelerate
}
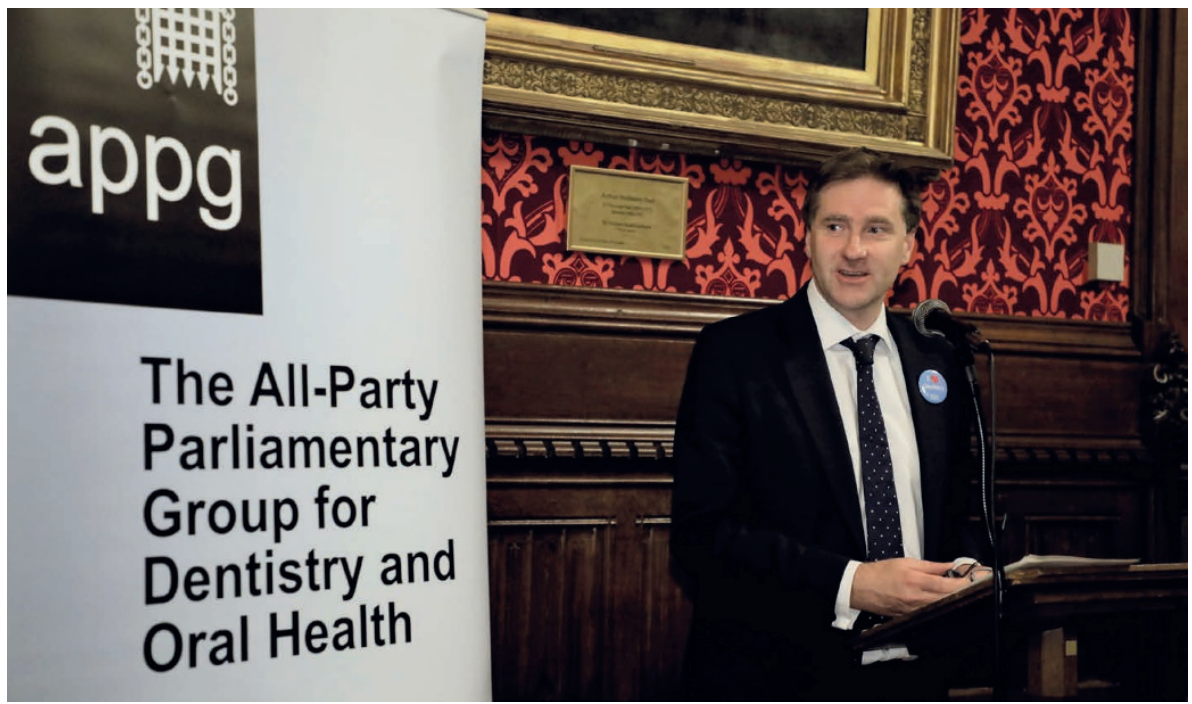

Steve Brine at APPG event

The pace of the dental contract reform process could accelerate thanks to the new health and social care secretary's focus on prevention of poor health in line with the new contract's preventative approach, according to a government minister.

Public health minister Steve Brine, whose remit covers dentistry, has spoken of the government's prevention of ill health drive being 'supercharged' by the arrival of Matt Hancock as health secretary last summer.

Brine, speaking on 5 December 2018 at the All-Party Parliamentary Group for Dentistry and Oral Health's Christmas Reception at the House of Commons, London, said: 'We remain more committed than ever to improving children's oral health and the country's oral and dental health. That has been supercharged in a way by having a secretary of state with prevention at the heart of his mission.

'Last Christmas, I spoke about our manifesto commitments around improving children's oral health and delivering the new prevention focused dental contract.

'We have made some important progress. We have had a change of secretary of state since I last saw you and the new secretary says that one of his three main priorities is prevention.

'Tooth decay and gum disease are largely preventable so the whole prevention agenda sits perfectly with the plans for the new dental contract I would suggest, which is preventing dental disease at its absolute core.'

Brine told the audience that the evaluation $^{1}$ of the first year of prototyping of the new dental contract, published in May 2018 had been 'largely positive about the approach being tested'.

'On the back of this, we announced the recruitment of further prototype practices from October with more to follow from January', he said.

'We are being told by the profession and our advisors that the prevention focused clinical pathway is the right approach to delivering the better care for patients that we both want. It is allowing dentists to deliver dentistry in a way that they are taught in dental school.

'If the patient is in control of their own oral health with the support of their dentist and the wider dental team, that is firmly in line with our prevention agenda. Dentists are finding it, I hope, a more clinically rewarding way of working and patients seem to like it.'

On the issue of how to progress, he admitted that the main questions continued to be around 'ironing out the remuneration model ensuring that we've got a model that is financially sustainable for dental practices and the NHS in the long term'.

'We will continue to work on that to get it right,' he said. 'We welcome the close engagement we are getting from the profession in testing out the contract and in helping to assure us of its viability before we make crucial decisions on oral health in April 2020.

'I know people are frustrated with the speed of it. With the dental contract, we have got one chance to get it right and if we get it wrong, we will lose the confidence of the profession and then we will be back to square one. It is slow, but it will be got right.'
The government had recently published its prevention is better than cure vision document $^{2}$ and that had reinforced its commitment to improve children's dental health, he told the audience.

'A consultation will follow early next year [2019] when we produce a green paper and I want the dental profession to be very closely involved in that.'

Brine also referred to the child obesity plan and ongoing efforts to reduce sugar content in some foods and drinks, saying: 'Over half of products in the scope of the soft drinks industry levy - otherwise known as the sugar tax - have been reformulated.

'It's a huge effort from industry and a really good response to the challenge that we set them and that has removed some 45 million kilogrammes of sugar every year from sugary drinks. Excellent work, but there is more still to do.

'We have had a massive response to our consultation on ending the sale of the high sugar energy drinks to children. We will respond to that in due course.'

The government would also consult shortly on restricting promotions and advertising to children of children's food or drinks that are high in fat, salt or sugar, including consulting on whether to bring in a $9 \mathrm{pm}$ watershed on such advertising.

Speaking after the minister at the event, BDA chairman Mick Armstrong said: 'I work in Castleford, which produces one billion After Eight mints and a thousand tonnes of Haribo sweets a year. I am not sure that reformulation with a $30 \%$ reduction [in sugar] will have that big of an effect on the rate of caries.

'I agree that there is much more that we could do. I would like to see sugar treated like tobacco and I know that is a big step for government but it took us 30 odd years to realise the harm that tobacco was doing. We shouldn't wait 30 years to have a similar assault on sugar.'

By Adrian O'Dowd

1. Department of Health and Social Care. Dental contract reform: evaluation report 2016 to 2017. 2018. Available at https://www.gov.uk/government/publications/dental-contract-reform-evaluation-report-2016-to-2017. (accessed December 2018).

2. Department of Health and Social Care. Prevention is better than cure. 2018. Available at https://assets.publishing. service.gov.uk/government/uploads/system/uploads/ attachment_data/file/753688/Prevention_is_better_ than_cure_5-11.pdf (accessed December 2018). 